\title{
Projected wave climate temporal variability due to climate change
}

\author{
Andrea Lira Loarca • Manuel Cobos • \\ Giovanni Besio • Asunción Baquerizo
}

Received: date / Accepted: date

\begin{abstract}
This work proposes a new general procedure to stochastically analyze multi-model multivariate wave climate time series projections at different temporal scales. For every projection, it characterizes significant wave height, peak period and mean direction by means of univariate non-stationary distributions capable of capturing cyclic climate behavior over a reference time interval duration. The temporal dependence between the values at a given sea state and previous short-term wave climate is described with a vector autoregressive model (VAR). The multi-model ensemble wave climate characterization is based on a compound distribution of the individual non-stationary distributions and a weighted averaged VAR model. The methodology is applied to bias-adjusted wave climate projections derived using WaveWatch III forced by wind field data from EURO-CORDEX models at a location close
\end{abstract}

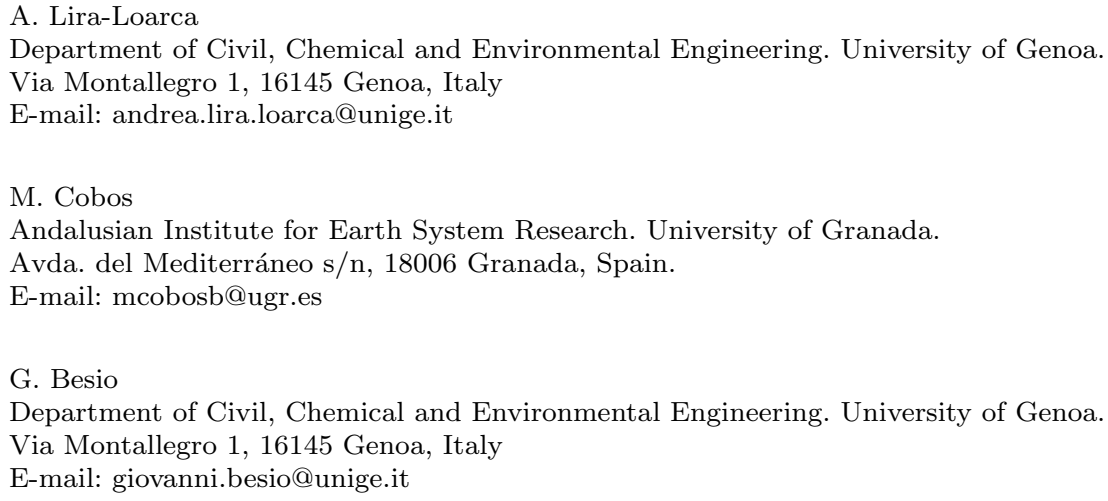

\section{A. Baquerizo}

Andalusian Institute for Earth System Research. University of Granada.

Avda. del Mediterráneo s/n, 18006 Granada, Spain.

E-mail: abaqueri@ugr.es 
to the Mediterranean Spanish coast. Results are compared to hindcast data which shows a clear bi-seasonal behavior. Different temporal references were considered, starting with a 1-year reference period to analyze overall changes in wave climate at scales ranging from days, months and seasons with respect to historic conditions. The results show that the projected wave climate has a very different temporal behavior than hindcast data, delaying and widen-

$25 \mathrm{ing} /$ shortening the start and duration of the two main seasons and including shorter term variations. Regarding the energetic content of the sea states, the compound variable highest percentiles of the significant wave height present lower values than the hindcast $(\approx 3-10 \%)$ during the traditionally more severe period (November-March) but higher values $(\approx 10-35 \%)$ during the calmer

so months. The projected peak period presents a similar temporal pattern to the hindcast data, while the mean wave direction shows a significant change from the historical bi-modal behavior towards more likely easterly waves throughout the year. Additionally, a 10-year analysis is done to find larger temporal variabilities such as decadal variations associated with the North Atlantic

35 Oscillation. The observed temporal variability in the yearly seasonal pattern throughout the century is addressed by analysing 20-year rolling windows in all the model projections and in the compound variable. The compound distribution shows significant temporal variabilities throughout the century with the most severe periods and more likely severe waves during summer at the 40 end of the century.

Keywords future wave climate $\cdot$ climate change $\cdot$ temporal variability · non-stationary $\cdot$ multivariate analysis

\section{Introduction}

Coastal regions are particularly vulnerable to climate change with expected im45 pacts not only associated to global mean sea-level rise and permanent flooding of low-lying areas but also to the occurrence of extreme wave climate (Vitousek et al., 2017; Vousdoukas et al., 2020). Coastal risks, understood as the probability of unwanted consequences, are particularly high as around 680 million people (approximately 10\% of the global population) resides in coastal regions 50 $(<10 \mathrm{~m}$ above sea level) with a projection to reach more than one billion by 2050 (IPCC, 2019). Therefore, a crucial step towards coastal planning and adaption is the understanding of extreme wave events drivers and impacts in a changing climate.

Climate change is expected to affect wind patterns and storm characteris55 tics, and it will, therefore, modify wave climate and its contribution to relative sea levels, sediment dynamics and shoreline processes in coastal regions. According to the IPCC Special Report on the Ocean and Cryosphere in a Changing Climate, extreme events that historically occurred once per century combining sea level, tides, surges and waves, are projected to become at least annual events at most parts of the world during the 21st century (Oppenheimer 
et al., 2019). Changes in wave climate severity and particularly in the incoming direction may also alter the sedimentary dynamics and shoreline processes in coastal regions, exacerbating morphological changes including erosion.

When addressing climate change coastal impacts, it is key to include and 65 analyze the future changes to the multivariate wave climate as well as its nonstationarity on different temporal scales as wave patterns are often described as the prevailing drivers of coastal changes (Mentaschi et al., 2017; Melet et al., 2020). The knowledge of projected wave climate and changes in storminess is limited relative to other climate variables given the difficulty to predict their 70 large interannual and decadal variability (Bricheno and Wolf, 2018; Morim et al., 2018). In recent years, studies have focused on the characterization of future changes in global significant wave height, its occurrence and magnitude but there is still a lack of knowledge regarding wave period and direction and their contribution to extreme sea levels and coastal stability (Collins et al., 75 2019).

Wave climate has a wide range of temporal variability. Lira-Loarca et al. (2020) proposed a methodology to characterize, from observations or hindcast time series, the main wave variables and their temporal dependence under storm conditions by non-stationary mixture distribution functions and

so a vector autorregressive model (hereinafter VAR) at intra-annual scale. Their work allowed to adequately reproduce the random temporal evolution of storm events, crucial for the study of coastal impacts and damage evolution on marine structures. Melet et al. (2018) analyzed the contribution of wave setup to the changes in coastal sea levels on interannual to multidecadal timescales 85 and highlighted the need to analyze further the wave contribution to total sea levels and their temporal variability.

Morim et al. (2019) presented an ensemble of global wave climate projections from a coordinated and multi-method statistical and dynamical downscaling of Global Climate Models (GCMs) surface wind fields. Their results 90 highlighted the importance of the multivariate wave climate analysis as $\approx 40 \%$ of the world's coastline presented robust changes in the significant wave height, wave period and/or mean direction. They analyzed the uncertainties derived from different components including the use of GCMs wind fields with spatial resolutions of $\approx 1-2^{\circ}$. Furthermore, the results showed that storm wave 95 climate is not adequately captured in certain regions with such coarse resolutions. Therefore, wave models driven by higher-resolution wind fields are needed to properly resolve the wave field transformations as they propagate into shallow waters and to provide appropriate characterizations of extreme events for coastal applications (Bricheno and Wolf, 2018; Melet et al., 2020).

100 The international CORDEX (Coordinated Regional Climate Downscaling Experiment) initiative has provided an ensemble of climate simulations with high spatial resolution Regional Climate Models (RCM) in different regions around the globe. In Europe, the EURO-CORDEX initiative provides a large ensemble of atmospheric simulations with a spatial resolution of $0.44^{\circ}(\approx 50 \mathrm{~km})$ and $0.11^{\circ}(\approx 12.5 \mathrm{~km})$ for the different RCP scenarios (Jacob et al., 2014). 
Global climate models are the primary tools to investigate the response of the climate system to different forcing, and are therefore suitable for quantitative future predictions and projections. In addition, regional downscaling methods provide climate information at the smaller scales needed for many climate impact studies (Cubasch et al., 2013). An individual GCM or RCM simulation represents only one of the possible climate system pathways due to uncertainties that arise from internal variability, boundary conditions, parameters for a given model structure, among others. Ensemble methods allow to assess these uncertainties by including larger samples with different methodologies (physical phenomena, modelling processes and initial conditions). Multimodel ensembles address structural uncertainty and internal variability by using model simulations from multiple climate modelling centres. The most common approach to characterize multi-model ensemble results is through an unweighted multi-model mean following a 'one model, one vote approach' regardless of the individual model performance (Flato et al., 2013). The reliability of the ensemble can be improved by weighting models according to their adequacy to reproduce some phenomena or their membership to a certain set (Knutti et al., 2010; Tegegne et al., 2020) with a multitude of techniques aimed at it but there is no consensus in the scientific community about how to assign likelihood to different model projections (Christensen et al., 2010; IPCC, 2013).

We propose a methodology to statistically characterize a multi-model GCMRCMs ensemble of wave projections in a climate change scenario by means of compound variables. The procedure is based on the works by Solari and Losada (2011), Solari and Van Gelder (2011) and Lira-Loarca et al. (2020) for the non-stationary characterization of multivariate random series and extended to include different temporal variabilities. In order to highlight the potential of the methodology, it is applied to a case study in the Mediterranean sea with wave projections obtained with the Wavewatch III model driven by the atmospheric forcing of seven EURO-CORDEX models (GCM-RCM combinations) for RCP8.5.

The paper is organised as follows. Section 2 presents the different methodologies included in this work to analyze future wave climate with 7 different GCM-RCM wave projections under RCP8.5 (§2.1) using non-stationary statistical characterization of the main wave variables and their temporal multivariate dependence $(\$ 2.2)$ and the multi-model ensemble multivariate characterization (§2.3). Section 3 presents the results from applying the methodology to a case study in the Mediterranean coast of Spain and the comparison to hindcast conditions. The discussion regarding the different methods and results is presented in section 4 . Finally, section 5 summarizes the main conclusions from this work. 


\section{Materials and methods}

We analyze local wave climate that is described by multivariate time series of sea state descriptors such as the significant wave height, $H_{s}$, the peak period, $T_{p}$, and the mean incoming wave direction, $\theta_{m}$ at a given ocean location, as it is customary in coastal engineering. Wave climate projections in the Mediterranean sea are obtained using the WaveWatch III model for 7 different GCMRCMs under RCP8.5. The analysis comprises the time-dependent stochastic characterization of wave climate for each GCM-RCM using non-stationary 5 probability models and the temporal dependence between variables by means of a VAR model. A Bayesian approach is used to describe the multi-model random variables as compound variables.

\subsection{Wave climate projections}

Wave projections were generated with the spectral wave model Wavewatch III (version 5.16; Tolman and The WAVEWATCH III ${ }^{\circledR}$ Development Group (2016)) driven by the atmospheric forcing from the following seven EUROCORDEX models (GCM-RCM combinations) for RCP8.5:

Table 1 EURO-CORDEX RCM and driving GCM combinations and notation used.

\begin{tabular}{cccc}
\hline Institution & RCM & GCM & Notation \\
\hline CLMcom & CCLM4-8-17 & CCCma-CanESM2 & CCLM4-CanESM2 \\
CLMcom & CCLM4-8-17 & MIROC-MIROC5 & CCLM4-MIROC5 \\
SMHI & RCA4 & MPI-M-MPI-ESM-LR & RCA4-MPI-ESM-LR \\
SMHI & RCA4 & NCC-NorESM1-M & RCA4-NorESM1-M \\
SMHI & RCA4 & CNRM-CERFACS-CNRM-CM5 & RCA4-CNRM-CM5 \\
SMHI & RCA4 & IPSL-IPSL-CM5A-MR & RCA4-IPSL-CM5A-MR \\
SMHI & RCA4 & MOHC-HadGEM2-ES & RCA4-HadGEM2-ES \\
\hline
\end{tabular}

The EURO-CORDEX ensembles is a large and comprehensive set of simulations particularly suitable for robustness studies of future climate and impact studies (Kjellström et al., 2016). For further details on the definition and performance of the Regional Climate Models used in this work, the reader is referred to Strandberg et al. (2014) for the Rossby Centre regional climate model RCA4 and Will et al. (2017) for the CLM-Community CCLM4-8-17 model.

The wave model setup consists of a grid with a $10 \mathrm{~km}$ resolution over the whole Mediterranean basin, with high-resolution nesting on specific areas using the source terms of growth/dissipation ST4 (Ardhuin et al., 2010; Rascle and Ardhuin, 2013; Mentaschi et al., 2015). The wave model was forced by 6 -hourly wind field data with $0.11^{\circ}$ resolution $(\approx 12.5 \mathrm{~km})$ from the models presented on Table 1.

The wave climate projections were bias-adjusted by means of distribution mapping (also known as probability mapping or quantile-mapping) to cor- 
rect the distribution function of the GCM-RCM projections to agree with the hindcast distributions (Teutschbein and Seibert, 2012; Lemos et al., 2020) as

follows:

$$
y^{*}=F_{\text {hind }}^{-1}\left(F_{R C M}^{\text {hist }}(y)\right),
$$

where $y^{*}$ are the bias-adjusted values of the original variable, $y, F_{\text {hind }}$ is the distribution function of the hindcast data and $F_{R C M}^{h i s t}$ is the distribution function of each GCM-RCM during the control period (1970-2005).

2.2 Non-stationary stochastic characterization of wave climate for an individual GCM-RCM

Multivariate time series of $H_{s}, T_{p}$ and $\theta_{m}$ are stochastically characterized comprising (i) the fit of univariate non-stationary mixture distributions $F_{H_{s}}$, $F_{T_{p}}$ and $F_{\theta_{m}}$ and (ii) a VAR model to describe the multivariate temporal dependence following the methodologies of Solari and Losada (2011); Solari and Van Gelder (2011) and Lira-Loarca et al. (2020).

The significant wave height $H_{s}$ distribution usually presents a different behavior between the central body and the tails. Then, it is fitted by a nonstationary mixture probability density function, composed by a Generalized Pareto Distribution (GPD) describing the tails with parameters $\xi_{\gamma}$ and $\sigma_{\gamma}(\gamma$

${ }_{195}=l$ and $u$ for the lower and upper tails respectively) and a Lognormal (LN) distribution for the central regime with shape, $e^{\mu_{c}}$, and scale, $\sigma_{c}$, parameters where $\mu_{c}$ and $\sigma_{c}$ are the mean and standard deviation of the variable's natural $\operatorname{logarithm}$. The peak period $T_{p}$, is fitted to a continuous parametric single nonstationary Lognormal distribution with parameters $e^{\mu_{T}}$ and $\sigma_{T}$ and the mean wave direction, $\theta_{m}$, is described by a sum of $N_{T N}$ non-stationary truncated normal (TN) functions limited to the interval $[0,2 \pi)$ with parameters $\mu_{i}, \sigma_{i}$, for $i=1, \ldots, N_{T N}$ where $N_{T N}$ is the number of main wave directions.

The univariate distributions of $H_{s}, T_{p}$ and $\theta_{m}$ are considered non-stationary over a reference temporal period of duration $Y_{\alpha}$ where $\alpha$ indicates the number of years. For this, each parameter of the distribution $a\left(a=\xi_{\gamma}, \sigma_{\gamma}, \mu_{c}, \cdots\right)$ is characterized as a time-dependent function whose Fourier series expansion truncated to $N_{F}$ oscillatory terms is:

$$
a(t)=a_{0}+\sum_{n=1}^{N_{F}}\left[a_{n} \cos \left(\frac{2 \pi n t}{Y_{\alpha}}\right)+b_{n} \sin \left(\frac{2 \pi n t}{Y_{\alpha}}\right)\right],
$$

where $a_{0}$ is the mean value and $a_{n}$ and $b_{n}$ (for $n=1, \ldots, N_{F}$ ) are the $n^{\text {th }}$ trigonometric (Fourier) coefficients associated to the harmonic component with cycle duration $Y_{\alpha} / n$. In mid-latitudes, the year is the main periodic climate variation and, therefore, taking $Y_{\alpha}$ equal to $\alpha$ complete years is the natural choice as it allows to capture periodic temporal variability in climate signals, 
including the seasonal, yearly and if $\alpha>1$, also of several years. Other reference periods can also be selected, for example, those associated with monsoons seasons in equatorial regions.

The short-term multivariate temporal dependence between wave climate variables is characterized by a stationary $\operatorname{VAR}(p)$ model that assumes a linear relationship between the multivariate sea state at a given time and some past sea states. The number of previous values to take into account, known as the order of the model $p$, is determined as the one with the lowest Bayesian Information Criterion (BIC) value. With this approach, the VAR model allows to characterize the temporal dependencies of the multivariate wave climate at short timescales ranging from some hours to a few days (Solari and Van Gelder, 2011). For a detailed description of the methods presented here, the reader is referred to Lira-Loarca et al. (2020).

\subsection{Non-stationary multi-model ensemble characterization}

In order to account for the uncertainty regarding the true state of nature, we adopt a Bayesian approach where the set of parameters of the probability models proposed in section 2.2 denoted by $\vec{a}$ are random variables themselves. Let us call $X \mid t$ the non-stationary maritime random variable under consideration $\left(X\left|t=H_{s}\right| t, T_{p} \mid t\right.$ or $\left.\theta_{m} \mid t\right)$ and assume that all the climate models are equally likely, so that the prior distribution of the parameters, $\vec{a}$, is a discrete uniform distribution. Then, the distribution of $X \mid t$ is a compound variable obtained as a weighted summation of the fitted distributions of each model, $F_{m}(x \mid t)$, with equal weights, $w_{m}=1 / N_{m}$ where $N_{m}$ is the number of models:

$$
F(x \mid t)=\sum_{m=1}^{N_{m}} w_{m} F_{m}(x \mid t) .
$$

The use of compound distributions allows to easily compute the $n^{\text {th }}$ order, non-centered moment as an ensemble average of the individual GCM-RCM moments:

$$
M_{X \mid t}^{n}=\sum_{m=1}^{N_{m}} w_{m} M_{X_{m} \mid t}^{n},
$$

and from them other statistics such us the standard deviation, $\sigma_{X \mid t}$ :

$$
\sigma_{X \mid t}^{2}=\sum_{m=1}^{N_{m}} w_{m} \sigma_{X_{m} \mid t}^{2}+\sum_{m=1}^{N_{m}} w_{m}\left(M_{X_{m} \mid t}^{1}-M_{X \mid t}^{1}\right)^{2}
$$

The temporal dependence of the compound variable at a given time with previous values of itself and the other variables is obtained as the ensemble mean of the matrices that describe the parameters of the VAR model of the GCM-RCMs. 


\section{Application to the case study}

245 The methodology is applied to analyze the projected changes in local wave climate in a location of the Mediterranean sea close to the coast of Spain, more specifically, with coordinates $3.608^{\circ} \mathrm{W}-36.66^{\circ} \mathrm{N}$ (Figure 1) located at the Alborán Sea.

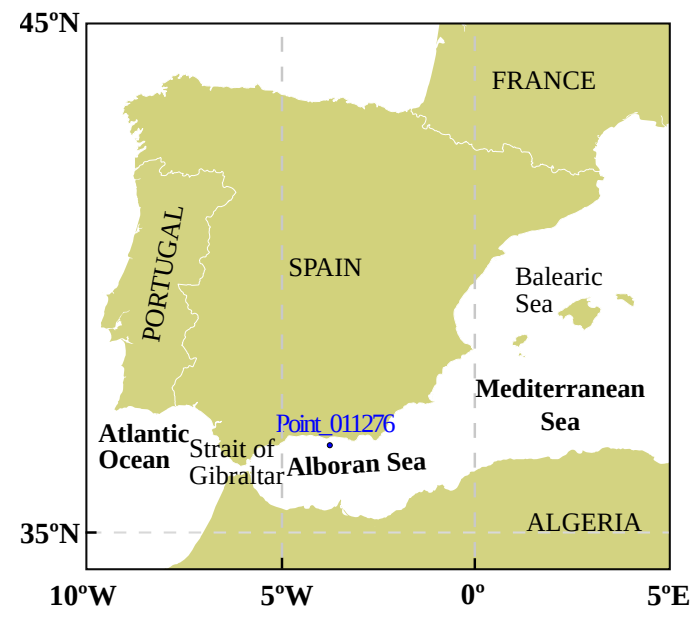

Fig. 1 Location of the study area

Wave climate time series of sea state descriptors $\left(H_{s}, T_{p}\right.$ and $\left.\theta_{m}\right)$ under the RCP8.5 scenario with 3-hour resolution from 2006 until 2100 forced by 7 different EURO-CORDEX GCM-RCMs are used. The results obtained by Lira-Loarca et al. (2020) using hindcast hourly data from January 1st, 1979 until December 31st, 2018 (Mentaschi et al., 2015) are also presented in this work for comparison.

3.1 Univariate non-stationary distributions and temporal variability over the year

The wave climate projections are fitted to non-stationary distributions for a 1-year reference period, $Y_{1}$ in order to analyze the temporal variability at scales that range from days to one year, including the seasonal variabilities.

${ }_{260}$ The Fourier series of the parameters in equation 2 are truncated to the fourth order according to the minimum BIC.

\subsubsection{Significant wave height}

Figure 2 presents a range of percentiles of the empirical and fitted LN-2GPD distributions of $H_{s}$ for the hindcast conditions and the projections with respect to a normalized year $Y_{1}=[0-1]$ and annual date [01/01-31/12]. It can be 
observed that data is adequately reproduced by the theoretical distributions for both the hindcast data and the GCM-RCMs projections.
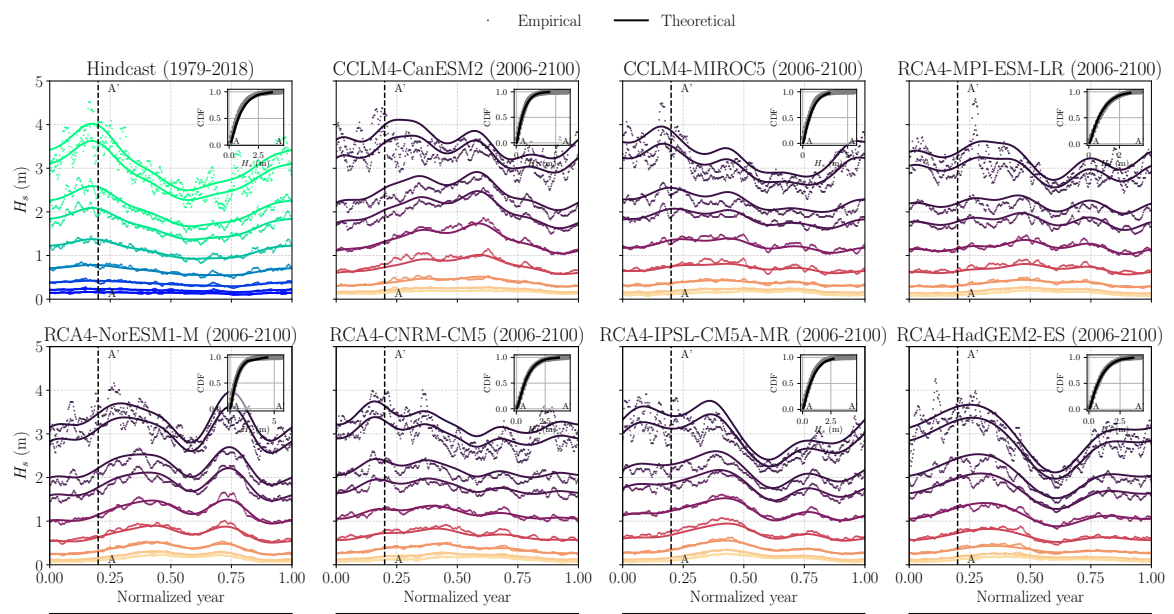

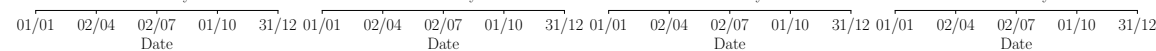

Fig. 2 Iso-probability percentiles $(5,10,25,50,75,90,95,99,99.5$ th) of the empirical and fitted non-stationary mixture distributions (LN-2GPD) for the significant wave height, $H_{s}$, for hindcast conditions and 7 different GCM-RCMs with respect to a normalized year $Y_{1}=[0-1]$ and annual date [01/01-31/12]. Each plot includes an inset of the stationary CDF for $\approx 15 /$ March $\left(Y_{1}=0.2\right)$.

The hindcast data presents a temporal pattern marked by two main seasons, with more likely higher waves around mid-March $\left(Y_{1}=0.2\right)$ and lower values in summer (July to end of August, $Y_{1} \approx 0.5-0.65$ ) with rather smooth transitions between seasons. This behavior is also present in the RCA4HadGEM2-ES, RCA4-IPSL-CM5A-MR and CCLM4-MIROC5 projections with slight phase shifts, but it is not exactly reproduced by the other models such as CCLM4-CanESM2 or RCA4-CNRM-CM5 which present a more uniform behavior throughout the year. For example, CCLM4-CanESM2 shows some oscillations from January to August $\left(Y_{1} \leq 0.6\right)$ for the higher percentiles and a slight decrease around mid-September $\left(Y_{1} \approx 0.7\right)$ followed up by a period of about three months where severe sea states are less likely to occur.

The results for the different GCM-RCMs show an overall decrease of the probability of occurrence of larger wave heights $H_{s}$ with respect to historical data in agreement with previous studies (Collins et al., 2019; Morim et al., 2019). A decrease of $\approx 3-10 \%$ with respect to hindcast data is observed for the different models for the highest percentiles except for CCLM4-CanESM2 for which slightly higher values $(\approx 4 \%)$ are observed. Regarding the variability for the rest of the year with respect to historical conditions, it can be highlighted that some models such as RCA4-MPI-ESM-LR, RCA4-CNRM-CM5 and particularly RCA4-NorESM1-M present an increase in the probability of 
higher values of $H_{s}$ during August-October $\left(Y_{1}=0.6-0.85\right)$ ranging from $\approx 10$ to $35 \%$.

The temporal variability of the projections and hindcast data can be further explored on the amplitudes and phases of the components of the Fourier expansion of the parameters of the distributions (Eq. 2) that are shown in Figures 3 and 4 . The figures include the representation of the parameters of the hindcast, each projection and the ensemble mean. The first column depicts the total time-dependent values of the parameters described by its mean value, on the $2^{\text {nd }}$ column, and the oscillatory terms on the following columns. The parameters of the Lognormal distribution fitted to the central body are shown in Figure 3. The parameters of the GPD distribution for the upper tail are also presented in Figure 4 as they are indicative of the more severe sea state climate. This information helps to unravel the changes in wave climate at different periodic time scales.

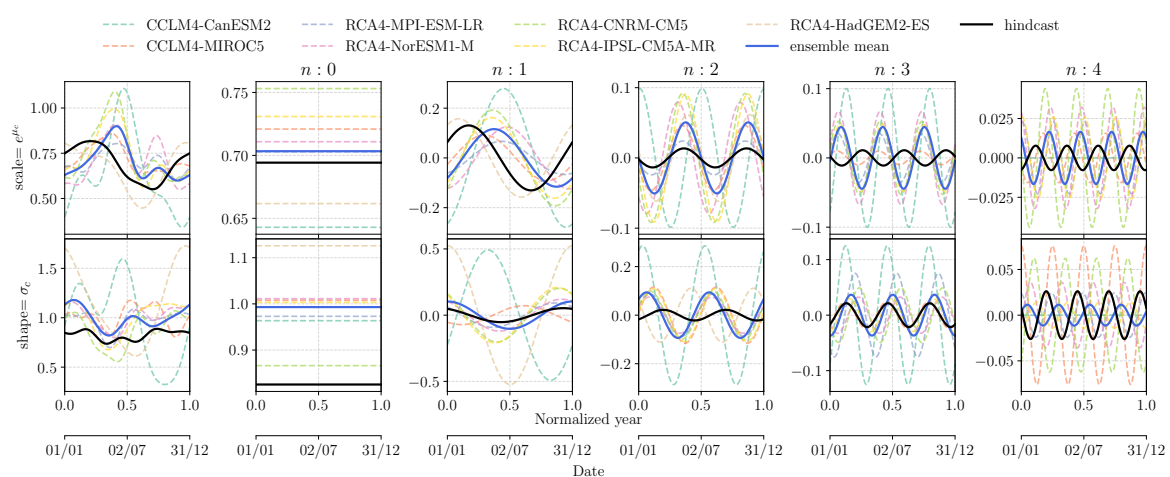

Fig. 3 Time-dependent values of the parameters of the LN distribution of the central regime of $H_{s}$. The first column is the complete Fourier series of the corresponding parameter, the second column represents the mean coefficient and the following columns are the oscillatory terms.

For the LN distribution, the mean values of the models ( $a_{0}$ in Eq. 2$)$ are quite similar and close to 0.7 and 1 , for the scale and shape, respectively. Regarding the scale parameter, hindcast data and RCA4-HadGEM2-ES show a similar seasonal variability $(n=1)$ while the remaining models, except CCLM4-MIROC5 and RCA4-NorESM1-M, show an amplification and a clear phase shift that, on average, is about three months. The ensemble mean shows slightly lower values than hindcast data and are shifted $\approx 2.6$ months. This phase lag can be observed directly in the peak of the intermediate percentiles of the compound distribution shown in Figure 5 and its effect on the position of the maximum values of the highest percentiles. This means that severe sea states are likely delayed about 2-2.6 months compared with the historical conditions. 
The semi-annual oscillations $(n=2)$ are amplified in almost all the models and, in general, are in phase with the corresponding hindcast component (except for CCLM4-CanESM2 which shows a shift of more than 2 months). Due to this, the iso-probability compound distribution percentiles show extra shorter-term oscillations that manifest themselves particularly from June to the end of December leadind to an increased frequency of storms during summer and autumn due to climate change.

The remaining components (of four and three months periods) are also amplified and show a phase shift with respect to hindcast data with the ensemble mean being out of phase. A similar behavior is observed for the shape parameter with the ensemble mean showing a similar pattern to hindcast for $n=1,3$ but phase shifted and out of phase, respectively, for 6 - and 3-months variability $(n=2,4)$. However, they have smaller amplitudes and their effect is less noticeable in the compound distribution.

Regarding the upper tail of the distribution (Fig. 4), almost all the models show a similar seasonal behavior with some phase shifts with respect to hindcast data in the scale parameter $\left(\sigma_{u}\right)$ and, again, the component of CCLM4CanESM2 is twice as large and out of phase. The shape parameter $\left(\xi_{u}\right)$ preserves the phase and is amplified in all the models for $n=1$.
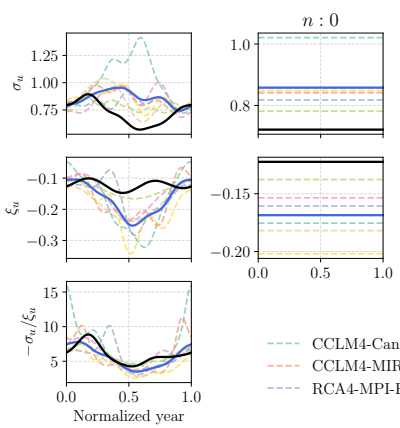

--- CCLM4-CanESM CCLM4-MIROC5 RCA4-MPI-ESM-LR
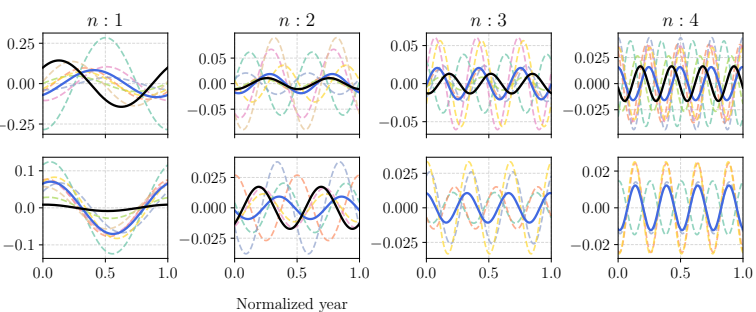

-.- RCA4-NorESM1-M RCA4-CNRM-CM5 RCA4-IPSL-CM5A-MR — ensemble me RCA4-HadGEM2-ES — hindcast

Fig. 4 Time-dependent values of the parameters of the GPD distribution of the upper-tail of $H_{s}$. The first column is the complete Fourier series of the corresponding parameter, the second column represents the mean coefficient and the following columns are the oscillatory terms.

With a negative shape parameter, the upper limit of the GPD is given by $\max \left(H_{s}\right)=-\frac{\sigma_{u}}{\xi_{u}}$. The values of this parameter over the year are also shown in Figure 4. As this parameter is obtained through a non-linear combination of the original parameters, its Fourier decomposition is not shown. By definition, relatively higher significant wave heights are obtained for the lowest and/or highest values of $\xi_{u}$ and $\sigma_{u}$, respectively. CCLM4-CanESM2, CCLM4MIROC5 and RCA4-MPI-ESM-LR show almost always larger values of this parameter with respect to hindcast data, with a time shift of the highest peak and more oscillations throughout the year, highlighting the changes in seasonality of the most severe sea state climate. The combined effect of the 
amplification of the amplitude of the yearly component of $\xi_{u}$ and the shift of the location parameter produces a delay of the peak of the highest percentiles to the end of April. The ensemble average presents, in general, slightly lower values than hindcast data. The maximum values of $-\sigma_{u} / \xi_{u}$ are found in winter but slightly phase shifted, e.g around mid-March for the hindcast and approximately in the beginning February for the ensemble average. This is consistent with the behavior described for the central regime.

Figure 5 presents the non-stationary stochastic annual behavior of the hindcast data and the compound variable defined as in Eq. 3 with equal weights. The figure also depicts the first order moment $M^{1}$ (Eq. 4) and standard deviation $\sigma$ (Eq. 5). In addition to the changes described previously, the compound variable presents a decrease of the probability of occurrence of larger wave heights $H_{s}$ during winter with respect to historical conditions $(\approx 5-10 \%)$ and slightly higher $H_{s}$ for lower percentiles. On the other hand, the compound variable shows higher $H_{s}$ values $(\approx 17-20 \%)$ during the traditionally calmer months. In summary, it shows a more uniform behavior over the year but still showing slight seasonal changes, in contrast with the already mentioned clear seasonal pattern of the hindcast data.

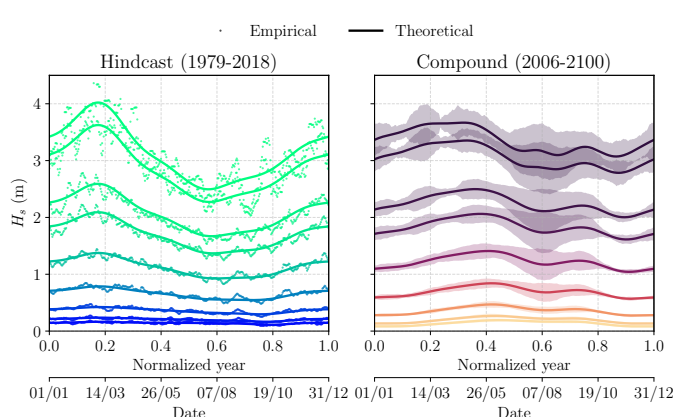

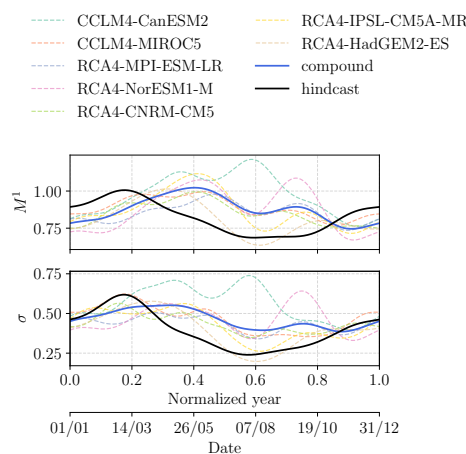

Fig. 5 Iso-probability percentiles $(5,10,25,50,75,90,95,99,99.5$ th $)$ of the empirical and fitted non-stationary mixture distribution (LN-2GPD) for the significant wave height, $H_{s}$, for hindcast conditions and compound variable projections including the uncertainty (one standard deviation of the different GCM-RCMs percentiles). Time-dependent values of the first-order moment and standard deviation of the fitted distribution functions for the hindcast, each GCM-RCM and the compound variable.

The first order moment of the probability distribution of the compound variable corresponds to its mean. The maximum presents a phase shift of about three months with respect to the hindcast maximum value. It also shows another incipient peak around mid-September $\left(Y_{1} \approx 0.7\right)$ not present in the historical data. A similar behavior is observed for the standard deviation with higher values for the compound variable during the traditionally warmer months indicating a higher spread of the data from the expected value. 


\subsubsection{Peak period}

Figure 6 presents the annual variability of some percentiles of the empirical and fitted non-stationary LN distribution of $T_{p}$ for the hindcast and the compound distribution including the uncertainty of the different GCM-RCM projections, quantified with one standard deviation. The results for each individual GCM$\mathrm{RCM}$ can be found in the Supplementary Information.

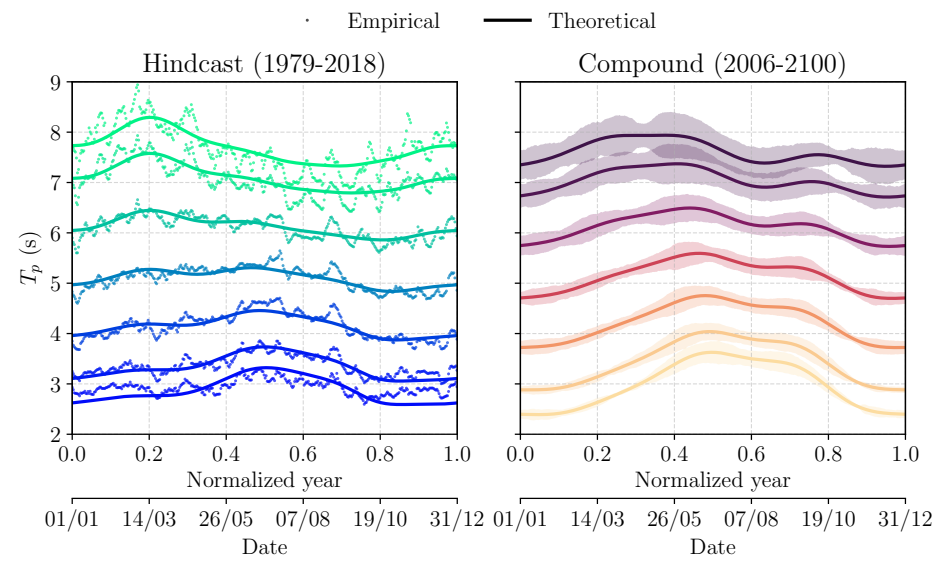

Fig. 6 Iso-probability percentiles $(5,10,25,50,75,90,95$ th $)$ of the empirical and fitted non-stationary distributions (LN) for the peak wave period, $T_{p}$, for the hindcast time series and compound variable including the uncertainty (one standard deviation of the different GCM-RCMs percentiles).

The hindcast higher percentiles show a pronounced peak around midMarch $\left(Y_{1} \approx 0.2\right)$. During summer, the lower percentiles show a peak from end of May to mid-September $\left(Y_{1} \approx 0.4-0.7\right)$, while the higher percentiles show a smooth valley. This means that in summer the range of variation of $T_{p}$ is almost restricted to values from 3 to $7 \mathrm{~s}$. The compound distribution, accordingly with the behavior shown for most of the models, presents a more uniform behavior throughout the year for the higher percentiles, with $\approx 4 \%$ more likely shorter waves from February to April $\left(Y_{1} \approx 0.1-0.3\right)$ with respect to hindcast data. It can be highlighted that the projections present an increase in wave periods from August until mid-October $\left(Y_{1} \approx 0.6-0.8\right)$ of $\approx 9 \%$ in comparison to hindcast data. 


\subsubsection{Mean wave direction}

Figure 7 shows the non-stationary empirical and fitted 2-TN distributions of $\theta_{m}$, for hindcast data and compound variable distribution including the uncertainty of the GCM-RCMs percentiles defined as one standar deviation.

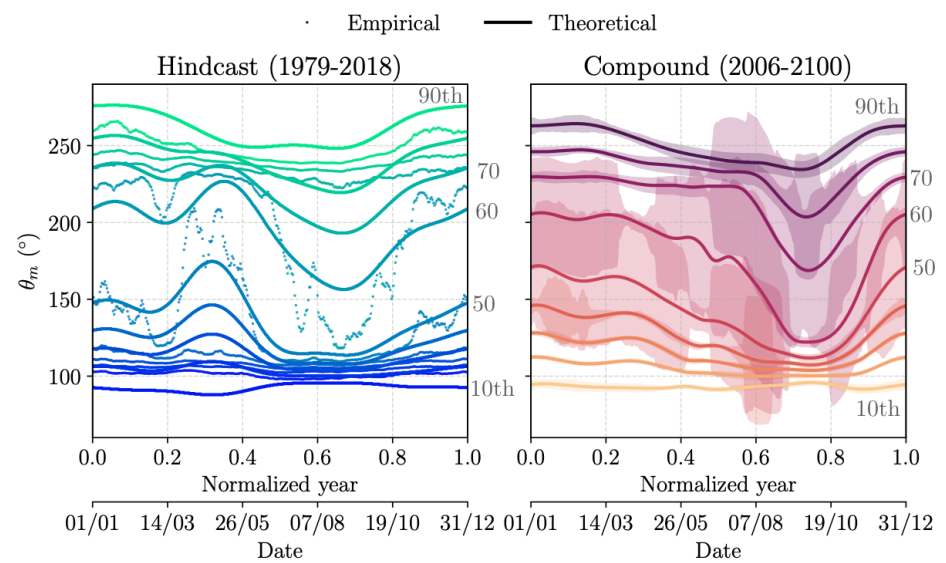

Fig. 7 Iso-probability percentiles $(10,20,30,40,50,60,70,80,90$ th $)$ of the empirical and fitted non-stationary distribution (2-TN) for the mean wave direction $\theta_{m}$, for the hindcast time series and compound variable including the uncertainty (one standard deviation of the different GCM-RCMs percentiles).

All the time series preserve the clear bimodal distribution with more likely values around $100^{\circ}$ (ESE) and $250^{\circ}$ (WSW) typical of the region (Losada et al., 2011; Lira-Loarca et al., 2020). The future climate shows a change from the historical bi-modal wave conditions towards more likely easterly wave throughout the year. The hindcast data presents values close to $100^{\circ}$ more likely than the $250^{\circ}$ highest percentiles. The range of values from the 2 nd quadrant widens in spring $\left(Y_{1} \approx 0.3\right)$ and the same occurs for directions from the 3rd quadrant from mid-July to November $\left(Y_{1} \approx 0.5-0.85\right)$. However, during this period of time, the dominant direction is close to $100^{\circ}$. This main seasonal variation in the historical conditions occurs at the end of May $\left(Y_{1}=0.4\right)$ and mid-October $\left(Y_{1}=0.8\right)$ and is also observed in the projections, with the transitions shifted in time with respect to hindcast. The compound distribution shows predominant $\mathrm{ESE}$ directions $\left(\theta_{m} \approx 100^{\circ}\right)$ throughout the year, with the 50th percentile not longer showing the change to westerly waves during spring as in the historical conditions. In addition, the compound projection shows a more pronounced seasonal transition compared to the hindcast data with changes in trends around August and the end of November $\left(Y_{1}=0.6\right.$ and $0.9)$. The standard deviation of the percentiles of the compound distribution 
largely varies throughout the year for the central body and also for the upper tail in summer time. This uncertainty is associated to the differences between GCM-RCMs model results for this particular variable, which are included in Supplementary Information.

\subsubsection{Multivariate temporal dependence}

The $\operatorname{VAR}(p)$ model captures the dependence of one variable at a given sea state with $p$ previous values of all the variables. Several orders were tested and the one with the smallest BIC value was selected, indicating the number of past hours that hold the strongest temporal dependence. Figure 8 shows, on the top, a dimensionless linear $\mathrm{BIC}$ value with respect to the number of past hours taken into account in the model, $\tau(h)$, for each GCM-RCM and the hindcast data. The optimum orders for each case are shown with symbols. For hindcast data, a given sea state is dependent on the values over the past $\tau=24$ hours. For the GCM-RCM wave climate projections, the optimum orders range from 30 to 54 hours with an average value close to 42 hours, indicating that wave climate at a given sea state is, on average, influenced by values of previous 42 hours on future wave climate under RCP8.5. Despite this apparent difference between projections and hindcast, for $\tau>18$ hours, the values of the coefficients for all GCM-RCMs are very close to zero, and differ approx. $10^{-4}$ from the preceding values.

Figure 8 presents, on the bottom, the values of the coefficients that show the dependence of the variables at $t$ with values at $t-\tau$, up to $\tau=18 \mathrm{~h}$. For the significant wave height, its dependence with $T_{p}$ and $\theta_{m}$ is relevant, showing that wave climate severity is associated to the mesoscale and synoptic atmospheric time scales (De Leo et al., 2020). For example, the dependence of $H_{s}(t)$ with $H_{s}(t-\tau)$ is higher, in absolute values, for $\tau \leq 3$ hours for the hindcast data and $\tau \leq 9$ hours for the projections. It is important to underline that the hindcast data is an hourly time series whereas the projections contain data every 3-hours. Therefore, it seems that the temporal dependence is given by the previous 3 sea states regardless of the temporal resolution of the time series. In the case of the dependence of $H_{s}(t)$ with $T_{p}(t-\tau)$, the projections show a higher dependence for more sea states and past hours (9 hours, 3 sea states) than the hindcast data ( 1 hour, 1 sea state). A similar behavior is observed for the dependence of $H_{s}(t)$ with $\theta_{m}(t-\tau)$, as well as the dependence of $T_{p}$ and $\theta_{m}$ with themselves and the other variables where the highest coefficients are obtained for the past hour (1 sea state) for the hindcast data and between 3-9 hours (1-3 sea states) for the projections. 

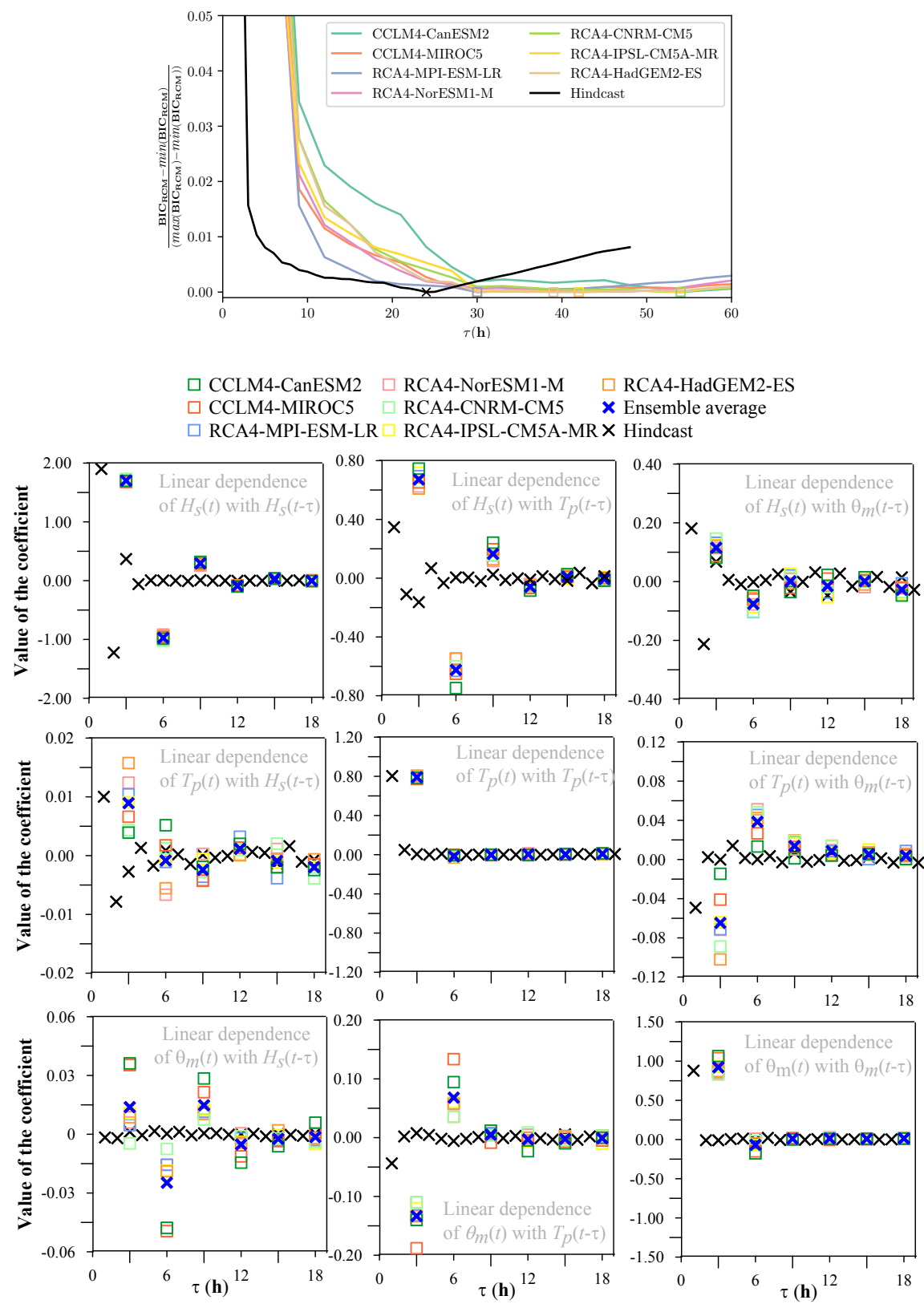

Fig. 8 Normalized Bayesian Information Criterion (BIC) with respect to the past $\tau$ hours (VAR model $p$ ) for the hindcast data and the different GCM-RCMs (top). Value of the parameters of the VAR model between the different variables and time points and with respect the past $\tau$ hours up to 18 (bottom). 
3.2 Long-term variability throughout the 21 st century

\subsubsection{Long-term temporal variability of $H_{s}$}

Wave climate usually shows longer term oscillations than the annual variability and inter-annual variability. Therefore, in order to analyze future long-term changes, the non-stationary analysis was also done taking 10 years as the reference time period, $Y_{10}$. Figure 9 shows the results of empirical and fitted LN-2GPD distributions for the 10-year reference period, and the 10-year oscillatory term of the parameters of the fitted LN (central body) and GPD (upper-tail) distributions for three GCM-RCM projections. For the sake of simplicity, only results obtained for the significant wave height are shown. All the models show the already described yearly oscillation (see section §3.1.1) and they also reveal longer period variabilities. The 10 -year oscillatory terms are of the same order of magnitude that the fourth order yearly term. This 10-year periodic pattern might be associated to the North Atlantic Oscillation (NAO) (Lionello and Sanna, 2005; Izaguirre et al., 2010) with similar magnitude as the seasonally pattern. The variability is particularly marked for RCA4-NorESM1-M with both the central regime and upper tail showing a similar 10-year behavior.

This analysis shows the capability of the methodology to capture, with the non-stationary distributions, time scale variations equal or smaller than the reference period $Y_{\alpha}$. However, it implicitly neglects the presence of longer time scales trends. Assuming that such longer variations are more gradual than $Y_{\alpha}$, it is possible to split the time series into several segments of length equal to a multiple value of $Y_{\alpha}$ with a certain overlap between them and to apply the methodology to each one in order to see a longer scale evolution as it is illustrated in section 3.2.2.

\subsubsection{Along-century variability of $H_{s}$ over a year reference period}

The yearly reference is of particular interest for management purposes. The analysis presented for $Y_{1}$ in section 3.1 includes the annual data from the range 2006-2100. The results show, therefore, an overall effect of climate change on the sea state descriptors at a yearly scale. Nonetheless, as it was seen previously, there are longer temporal variabilities present in the projections and therefore, the annual behavior is not expected to be uniform but to evolve throughout the 21st century. In an attempt to capture such evolution, the non-stationary stochastic distribution for the annual reference period $\left(Y_{1}\right)$ has been obtained for all the GCM-RCMs, using 20-year windows every 5 years.

480 Figure 10 presents the results of this analysis for model CCLM4-CanESM2 while the remaining models and compound variable are provided in the Supplementary Information. It can be observed for CCLM4-CanESM2, that the lower percentiles show relatively small variations over time but the higher ones do present important changes in magnitude and temporal variability through- 
Empirical Theoretical
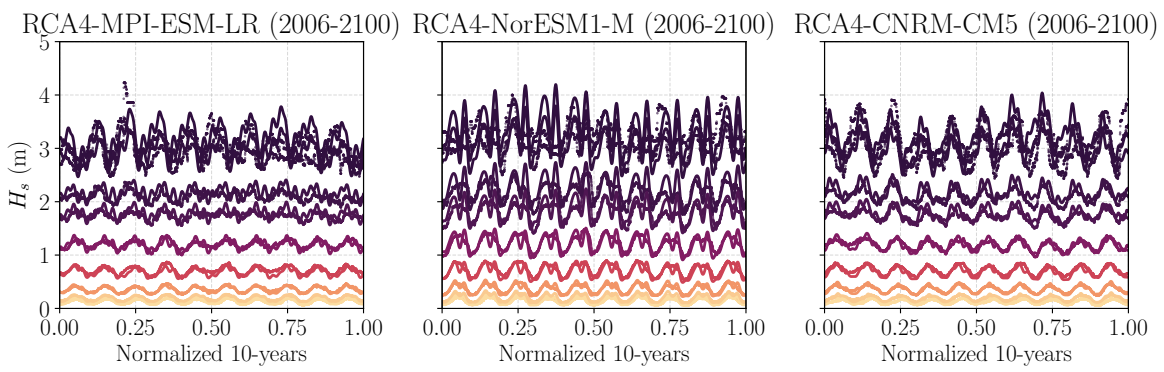

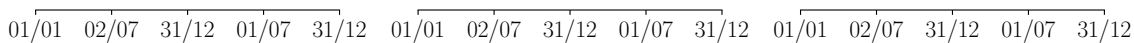

year01 year03 year05 year08 year10 year01 year03 year05 year08 year10 year01 year03 year05 year08 year10 Date

Date

Date

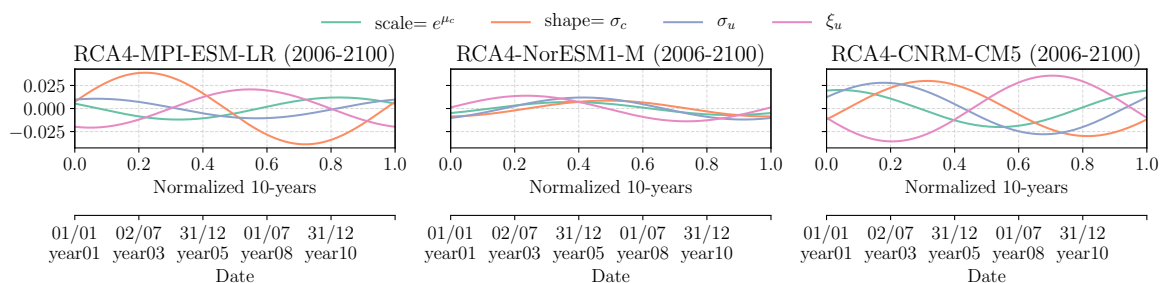

Fig. 9 Iso-probability percentiles $(5,10,25,50,75,90,95,99,99.5$ th $)$ of the empirical and fitted non-stationary mixture distributions (LN-2GPD) for the significant wave height, $H_{s}$, for 3 different GCM-RCMs for a 10-year reference period (top). 10-year oscillatory term of the parameters of the LN (central regime) and GPD (upper-tail) distributions of $H_{s}$ for each GCM-RCM.

out the century which is crucial for the implementation of short- and mid-term coastal adaptation and mitigation plans.

Figure 11 shows the corresponding evolution throughout the 21st century of the non-stationary 99th percentiles for the models CCLM4-CanESM2, RCA4HadGEM-ES and the compound variable. Each line represents, therefore, the variation in time of the wave height whose probability of exceedance is 0.01 for a 20 -year period. The $x$-axis indicates the middle year of the period. Although all the curves have the same scale, a colormap indicating the values of the significant wave height has also been included for reference. Some arrows have also been inserted to guide the reader in the interpretation of the results for 495 CCLM4-CanESM2.

For this model, it is observed that the projected wave climate stochastic features evolve over the century. A clear bi-seasonal behavior can be observed in the first two periods under consideration (2006-2026 and 2011-2031) with a defined severe climate period $\left(H_{s} \geq 3.8 \mathrm{~m}\right)$ of $4-5$ weeks starting around ebruary $\left(Y_{1} \approx 0.1\right)$ for the first period and about four weeks later for the second one. In both periods, there is a second time window with $H_{s} \leq 3.4 \mathrm{~m}$ that lasts about 5 months. For the third period (2016-2036), the most severe window is delayed to mid-March and extends for about 2.5 months, showing another incipient peak at the end of April. More oscillations are found during 
CCLM4-CanESM2

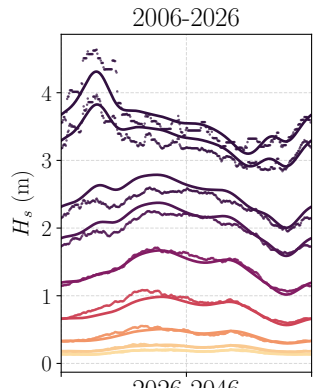

2011-2031

$2016-2036$

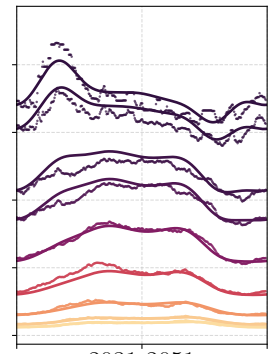

2031-2051
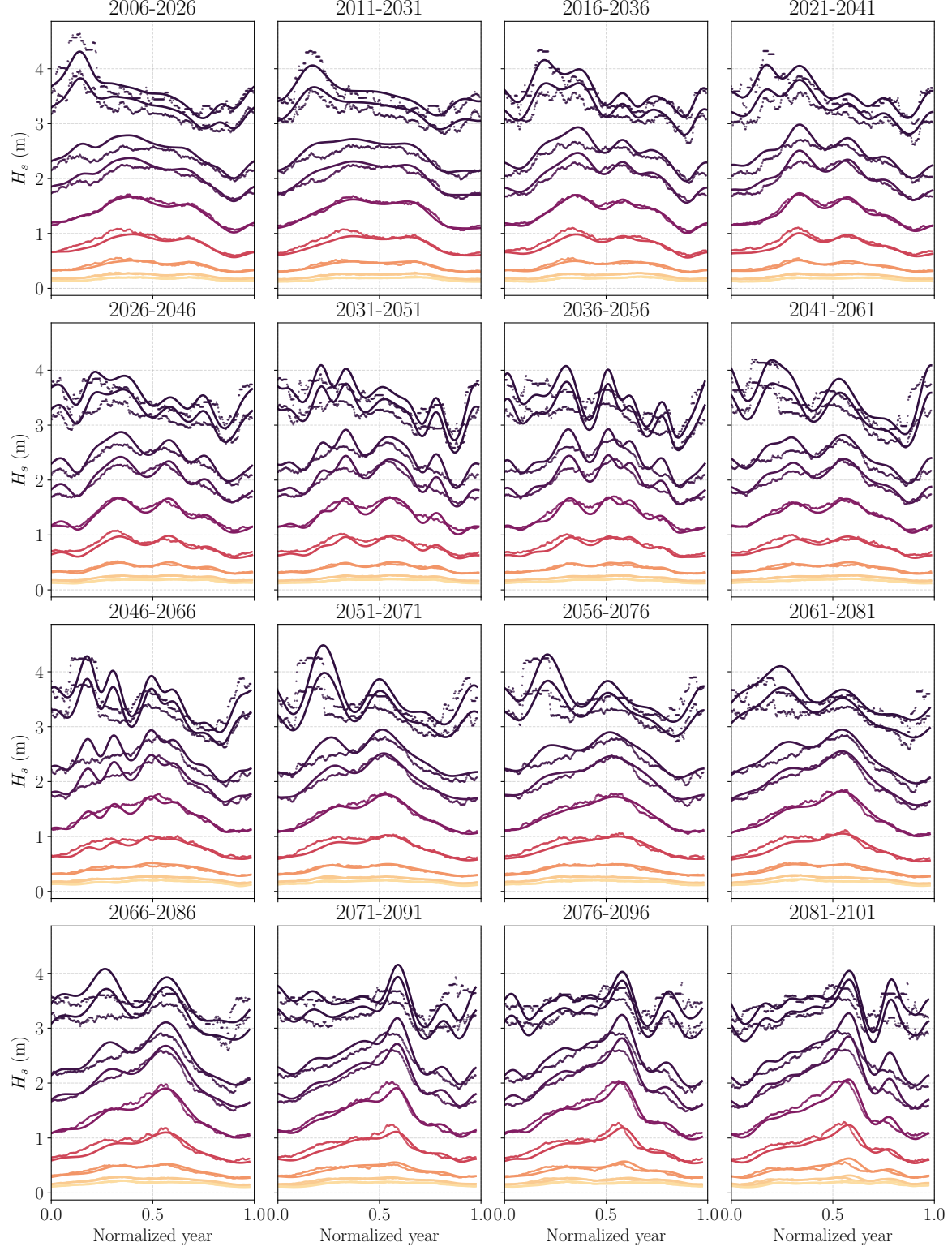

Fig. 10 Iso-probability percentiles $(5,10,25,50,75,90,95,99,99.5$ th $)$ of the empirical and fitted non-stationary mixture distribution (LN-2GPD) for the significant wave height, $H_{s}$, for 20-year rolling windows for the CCLM4-CanESM2 projection. The results for the rest of the models and the compound variable can be found in the Supporting Information. 

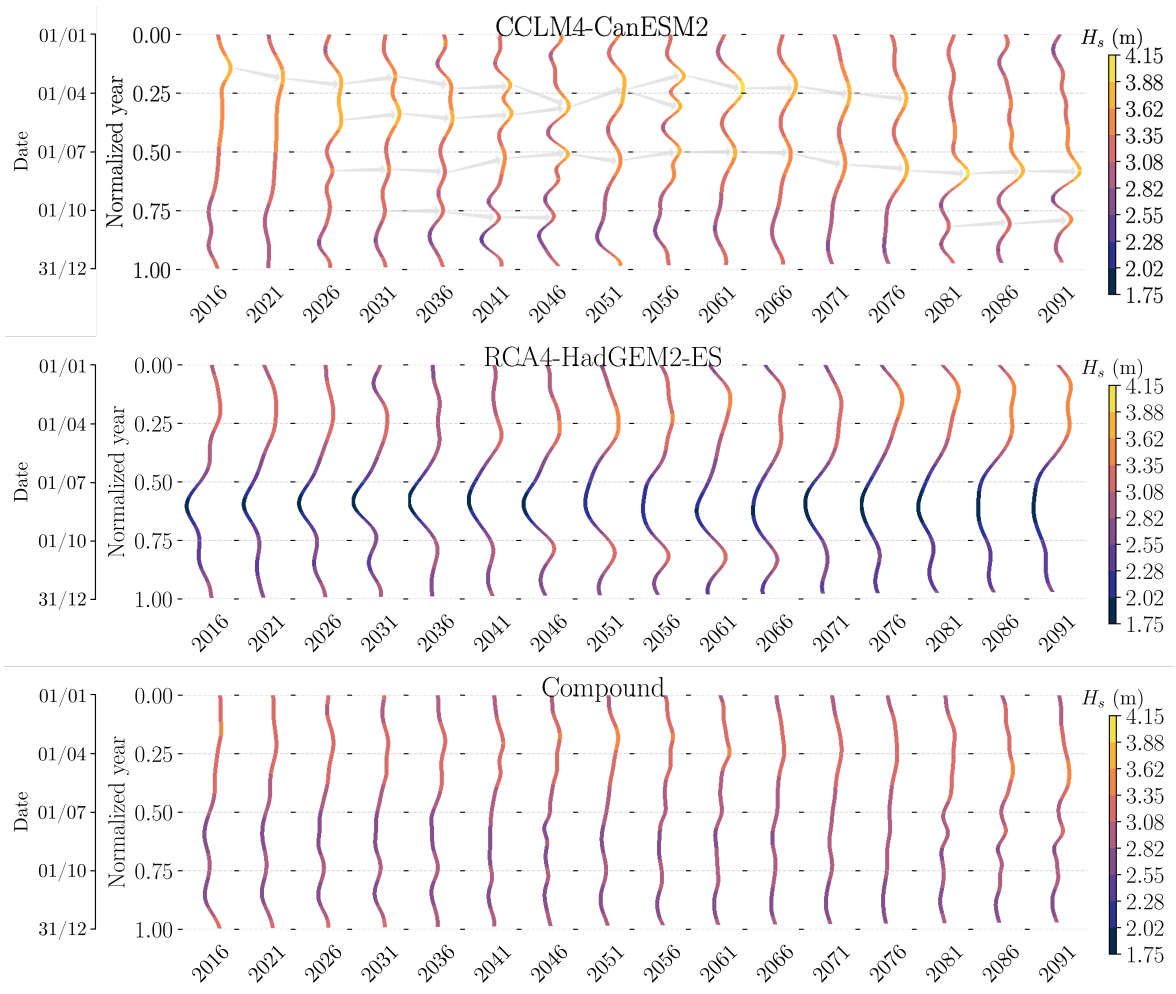

Fig. 11 Iso-probability 99th percentile of the fitted non-stationary mixture distribution (LN-2GPD) for the significant wave height, $H_{s}$, for 20 -year rolling windows for the CCLM4CanESM2 (top), RCA4-HadGEM2-ES (middle) and compound variable (bottom) projections. The $x$-axis depicts the middle year in the 20 -year window period. The results for the rest of the models can be found in the Supporting Information.

the rest of the year and the least severe month seems to be November. During the next three analyzed periods (2021-2041, 2026-2046 and 2031-2051), the two most severe peaks persist and are visible from mid-March to the end of May and for the rest of the year, more pronounced oscillations are present but still November remains as the month where the probability of occurrence of the highest storms is smaller (even up to the $12^{\text {th }}$ period ranging from 2061 to 2081). In the $7^{\text {th }}$ period (2036-2056) there is a tendency for increased severity of storms in May and another severe time window appears around July. This behavior of two well-distinguished severe time intervals is maintained until the $13^{\text {th }}$ period (2066-2086). From the $14^{\text {th }}$ period (2071-2091) until the end of the century, the first peak disappears and the second one is delayed to the beginning of August. The lasts two intervals (2076-2096 and 2081-2101) show an incipient 2nd peak at the end of October.

The results in Figure 11 for RCA4-HadGEM2-ES show less variations in regards to the seasons. The valleys, with the least severe waves, are centered around August, with some variability throughout the century. The main peak 
corresponding with a more likely severe climate remains in winter, with its peak advancing progressively until the $8^{\text {th }}$ period (2051) where is found at the beginning of April and seems to go back in time in the subsequent periods, widening its duration until mid-May. It can also be highlighted that a peak starts to develop in the $4^{\text {th }}$ period (2031) around October and it is accentuated until the $10^{t h}$ period (2061), and then it starts to attenuate until the end of the century when it can hardly be observed. Regarding the compound variable, the behavior of the 99th percentile is quite uniform in all the analyzed periods but slight changes in seasonality are observed as in the individual models. In the first period (2016), the most likely severe waves are found at the end of February and delayed and reduced in magnitude in the following periods up to the $6^{\text {th }}$ period (2041) where the most severe waves are found in mid-March. Different variabilities are observed for the following periods up to the end of century where the highest waves are found from mid-April until the end of May. In addition, for the periods at the end of the 21st century (2081, 2086, 2091), other incipient peaks are found later in the year around August and October.

\section{Discussion}

The methodology for the non-stationary stochastic ensemble average characterization of multi-model bias-adjusted wave climate projections was applied to analyze the future wave climate temporal variability. It uses time series of sea state descriptors, in particular, the significant wave height $H_{s}$, wave peak period $T_{p}$ and mean direction $\theta_{m}$. For the sake of simplicity, only these three variables have been included, but additional ones such as the mean wind speed and mean wind direction can also be included in the multivariate analysis. The methodology can also be applied to other set of climate variables. The results are presented for a point in the Mediterranean sea but, given the statistical character of the methodology, it is suited to be applied to any other location of the ocean where projections are available, as long as the data has an adequate length to perform a reliable analysis.

Following the recommendation given by Lemos et al. (2020) and as customary for climate and hydrological impact studies (Teutschbein and Seibert, 2012), wave data was bias-adjusted. In this work the distribution mapping methodology was applied using fitted stationary distribution functions for each variable, but any other bias-adjustment method can be used or, given the lack of consensus on the use of bias corrections methods for sea climate variables, raw data from GCM-RCMs can be the input for the presented methodology. The non-stationarity is accounted for by approximating the time-dependent functions that describe the temporal variations of the parameters of the distributions to truncated Fourier expansions (Eq. 2) as in Solari and Losada (2011). This choice is suitable as the given temporal functions are continuous and do no show abrupt changes. Alternative approaches can be used for other type of variables if continuity cannot be guaranteed. 
The wave climate temporal variability was analyzed taking 1 year and 10 tions), captures longer time scales variations, probably associated to the NAO oscillation (Lionello and Sanna, 2005; Izaguirre et al., 2010). With the available time series length for the projections, it is not possible to analyze, with enough statistical confidence, longer periods of time. In addition, the methodlonger than the reference time period. To overcome this limitation, it is also proposed to analyze the long-term evolution throughout the century of the sea state descriptors taking $Y_{1}$ as a reference time unit given its interest for several management purposes. For that case, 20-years duration rolling-windows every series have to be used to obtain statistically representative results.

The use of a compound variable with equal weights assigned to each model associated to the commonly used rule of 'one model-one vote', as recommended by the IPCC (Stocker et al., 2013) attenuates the temporal variability of models which individually show strong variations. This choice, however, implicitly assumes that individual models are independent from each other (Tegegne et al., 2020), when in fact some of them share procedures and parameters to model particular processes (Sanderson et al., 2017), which questions this assumption. The proposed methodology can be used with any other combination of weights, depending on the specific site and knowledge about climate change processes. The analysis of the selection of weights, is, however, out of the scope of this paper.

The strongest and more significant short-term temporal dependence is obtained for the preceding 1-3 sea states for both hindcast and projections and ranges up to 24 and 42 hours for the hindcast and projections, respectively. This highlights the need to include multivariate analysis in future wave climate characterization. This short-term temporal dependence is related to the storms duration and has important implications on damage evolution of coastal structures and coastal erosion, among other issues. Considering the different climate processes involved in the frequency and persistence of extreme events, there is still low confidence on the regional storm changes (Oppenheimer et al., 2019) but this methodology can be used to shed some light into short period changes in storminess.

The climate change effects over the incoming wave direction have important implications in dynamics of the coastal area under study, particularly at deltas where the equilibrium planform strongly depends on the alternation of easterlies and westerlies sea states (Losada et al., 2011).

Finally, this methodology provides the elements for the full temporal simulation of multivariate wave climate under different RCPs, which is crucial to study, from a probabilistic and long term perspective, many processes of interest in coastal engineering and perform risk analysis. This is the case when addressing cumulative processes such as damage progression in maritime structures (Lira-Loarca et al., 2020) and coastal evolution planform (Baquerizo and Losada, 2008; Félix et al., 2012), and also in harbor operativity and manage- 
ment studies (Solari et al., 2011; García Morales et al., 2014; García-Morales et al., 2015).

\section{Conclusions}

The methodology presented for the non-stationary multivariate stochastic ensemble average characterization has been applied to a EURO-CORDEX GCM-

RCM multi-model set of seven bias-adjusted wave climate projections under RCP8.5 at a location close to the Spanish Mediterranean coast in the Alborán sea using 1 and 10 years as reference time periods. The analysis of the full available time series (2006-2100) shows the overall expected climate change effects over wave conditions. The analysis shows the capability of the methodology to capture the non-stationary stochastic wave climate variability over different temporal scales.

On an annual scale, projections show a clear modification of the typical bi-seasonal behavior of the wave climate in the area, showing changes in all the analyzed sea state descriptors $\left(H_{s}, T_{p}, \theta_{m}\right)$. Most of the GCM-RCMs show a time shift and an reduction/amplification of the quantiles seasonal variation with respect to hindcast data, and some of them include additional pronounced shorter variations that have already been observed in historical data and in the along-century evolution analysis. This seasonal shift in the future climate in the Mediterranean regions has also been observed by Rocha et al. (2020) in the precipitation pattern. While the projected peak period presents a similar temporal pattern with respect to hindcast data -although with more variability for higher periods-, wave direction shows a significant change from the historical bi-modal wave conditions towards more likely easterly waves throughout the year. The 10-year analysis captures decadal temporal variabilities that might be associated with the North Atlantic Oscillation.

The VAR model allows to analyze the multivariate $\left(H_{s}, T_{p}, \theta_{m}\right)$ wave climate at shorter timescales (from hours to a couple of days). The results showed that a given sea state has the strongest temporal dependence with the previous 24 hours in the case of the hindcast data. For the projections, the main temporal dependence is given for a mean value of 42 hours, although from 18 hours onward, insignificant changes are obtained. Nonetheless the highest values of the parameters of the model are present for the preceding 1 to 3 sea states for all the cases.

The temporal variability over longer time scales is also analyzed over 20year rolling windows every 5 years, using $Y_{1}$ as a reference period. Results of the 99th percentile are presented for two individual GCM-RCMs with a clear differentiated behavior and also for the compound distribution. The RCA4-HadGEM2-ES projection, maintains, in general terms, the bi-seasonal behavior, with peak values almost in the same position of the year, but with changes in the duration and showing incipient additional peaks. The results for CCLM4-CanESM2 are rather surprising as they show a consistent shift in time of the peaks of the seasons, combined with a widening of their duration 
with certain periodicity over the century. Also, an extra peak around the so called Indian Summer (already reported by Rizou et al. (2015), among others) lays along the remaining years. Regarding the compound variable, it shows a more uniform behavior throughout the year with significant winter temporal variabilities along the century and more likely severe waves during summer at the end of the century.

Acknowledgements This work was performed within the framework of the project AQUACLEW, which is part of ERA4CS, an ERA-NET initiative by JPI Climate, and funded by FORMAS (SE), DLR (DE), BMWFW (AT), IFD (DK), MINECO (ES), ANR (FR) with co-funding by the European Commission [Grant 690462].

The hindcast and projections data used in this work were provided by the MeteOcean group ${ }^{1}$ of the University of Genoa.

\section{Conflict of interest}

The authors declare that they have no conflict of interest.

\section{References}

Ardhuin F, Rogers E, Babanin AV, Filipot JF, Magne R, Roland A, van der Westhuysen A, Queffeulou P, Lefevre JM, Aouf L, Collard F (2010) Semiempirical Dissipation Source Functions for Ocean Waves. Part I: Definition, Calibration, and Validation. Journal of Physical Oceanography 40(9):19171941

Baquerizo A, Losada MA (2008) Human interaction with large scale coastal morphological evolution. an assessment of the uncertainty. Coastal Engineering 55(7):569 - 580

Bricheno LM, Wolf J (2018) Future Wave Conditions of Europe, in Response to High-End Climate Change Scenarios. Journal of Geophysical Research: Oceans 123(12):8762-8791

Christensen J, Kjellström E, Giorgi F, Lenderink G, Rummukainen M (2010) Weight assignment in regional climate models. Climate Research 44:179-194

Collins M, Sutherland M, Bouwer L, Cheong SM, Frölicher T, Combes HJD, Roxy MK, Losada I, McInnes K, Ratter B, Rivera-Arriga E, Susanto RD, Swingedouw D, Tibig L (2019) Extremes, Abrupt Changes and Managing Risks, Cambridge University Press, Cambridge, United Kingdom and New York, NY, USA, chap 6

Cubasch U, Wuebbles D, Chen D, Facchini M, Frame D, Mahowald N, Winther JG (2013) Introduction, Cambridge University Press, Cambridge, United Kingdom and New York, NY, USA, book section 1, p 119-158

1 http://www3.dicca.unige.it/meteocean/hindcast.html 
De Leo F, Solari S, Besio G (2020) Extreme wave analysis based on atmospheric pattern classification: an application along the italian coast. Natural Hazards and Earth System Sciences 20(5):1233-1246

Flato G, Marotzke J, Abiodun B, Braconnot P, Chou S, Collins W, Cox P, Driouech F, Emori S, Eyring V, Forest C, Gleckler P, Guilyardi E, Jakob C, Kattsov V, Reason C, Rummukainen M (2013) Evaluation of Climate Models, Cambridge University Press, Cambridge, United Kingdom and New York, NY, USA, book section 9, p 741-866

Félix A, Baquerizo A, Santiago J, Losada M (2012) Coastal zone management with stochastic multi-criteria analysis. Journal of Environmental Management 112:252 - 266, DOI https://doi.org/10.1016/j.jenvman. 2012.05.033, URL http://www.sciencedirect.com/science/article/ $\mathrm{pii/S0301479712003714}$

García Morales RM, Baquerizo A, Losada M (2014) Port operationality and safety analysis under uncertainty. Coastal Engineering Proceedings 1(34), DOI 10.9753/icce.v34.management.31

García-Morales RM, Baquerizo A, Ángel Losada M (2015) Port management and multiple-criteria decision making under uncertainty. Ocean Engineering 104:31 - 39

IPCC (2013) Annex I: Atlas of Global and Regional Climate Projections, Cambridge University Press, Cambridge, United Kingdom and New York, NY, USA, book section AI, p 1311-1394

IPCC (2019) Summary for Policymakers, Cambridge University Press, Cambridge, United Kingdom and New York, NY, USA, chap SPM

Izaguirre C, Mendez FJ, Menendez M, Luceño A, Losada IJ (2010) Extreme wave climate variability in southern europe using satellite data. Journal of Geophysical Research: Oceans 115(C4)

Jacob D, Petersen J, Eggert B, Alias A, Christensen OB, Bouwer LM, Braun A, Colette A, Déqué M, Georgievski G, Georgopoulou E, Gobiet A, Menut L, Nikulin G, Haensler A, Hempelmann N, Jones C, Keuler K, Kovats S, Kröner N, Kotlarski S, Kriegsmann A, Martin E, van Meijgaard E, Moseley C, Pfeifer S, Preuschmann S, Radermacher C, Radtke K, Rechid D, Rounsevell M, Samuelsson P, Somot S, Soussana JF, Teichmann C, Valentini R, Vautard R, Weber B, Yiou P (2014) EURO-CORDEX: new high-resolution climate change projections for European impact research. Regional Environmental Change 14(2):563-578

Kjellström E, Bärring L, Nikulin G, Nilsson C, Persson G, Strandberg G (2016) Production and use of regional climate model projections - a swedish perspective on building climate services. Climate Services 2-3:15 - 29

Knutti R, Abramowitz G, Collins M, Eyring V, Gleckler P, Hewitson B, Mearns L (2010) Good Practice Guidance Paper on Assessing and Combining Multi Model Climate Projections, IPCC Working Group I Technical Support Unit. University of Bern, Bern, Switzerland.

Lemos G, Menéndez M, Semedo A, Camus P, Hemer M, Dobrynin M, Miranda PMA (2020) On the need of bias correction methods for wave climate

735 projections. Global and Planetary Change 186:103109 
Lionello P, Sanna A (2005) Mediterranean wave climate variability and its links with NAO and Indian Monsoon. Climate Dynamics 25(6):611-623

Lira-Loarca A, Cobos M, Losada MA, Baquerizo A (2020) Storm characterization and simulation for damage evolution models of maritime structures. Coastal Engineering 156:103620

Losada MA, Baquerizo A, Ortega-Sánchez M, Ávila A (2011) Coastal Evolution, Sea Level, and Assessment of Intrinsic Uncertainty. Journal of Coastal Research (59 (10059)):218-228

Melet A, Meyssignac B, Almar R, Le Cozannet G (2018) Under-estimated wave contribution to coastal sea-level rise. Nature Climate Change 8(3):234-239

Melet A, Almar R, Hemer M, Le Cozannet G, Meyssignac B, Ruggiero P (2020) Contribution of wave setup to projected coastal sea level changes. Journal of Geophysical Research: Oceans (125):e2020JC016078

Mentaschi L, Besio G, Cassola F, Mazzino A (2015) Performance evaluation of Wavewatch III in the Mediterranean Sea. Ocean Modelling 90:82-94

Mentaschi L, Vousdoukas MI, Voukouvalas E, Dosio A, Feyen L (2017) Global changes of extreme coastal wave energy fluxes triggered by intensified teleconnection patterns. Geophysical Research Letters 44(5):2416-2426

Morim J, Hemer M, Cartwright N, Strauss D, Andutta F (2018) On the concordance of 21st century wind-wave climate projections. Global and Planetary Change 167:160 - 171

Morim J, Hemer M, Wang XL, Cartwright N, Trenham C, Semedo A, Young I, Bricheno L, Camus P, Casas-Prat M, Erikson L, Mentaschi L, Mori N, Shimura T, Timmermans B, Aarnes O, Breivik Ø, Behrens A, Dobrynin M, Menéndez M, Staneva J, Wehner M, Wolf J, Kamranzad B, Webb A, Stopa J, Andutta F (2019) Robustness and uncertainties in global multivariate wind-wave climate projections. Nature Climate Change 9(9):711-718

Oppenheimer M, Glavovic BC, Hinkel J, van de Wal R, Magnan AK, AbdElgawad A, Cai R, Cifuentes-Jara M, Deconto RM, Ghosh T, Hay J, Isla F, Marzeion B, Meyssignac B, Sebesvari Z (2019) Sea Level Rise and Implications for Low Lying Islands, Coasts and Communities, Cambridge University Press, Cambridge, United Kingdom and New York, NY, USA, chap 4

Rascle N, Ardhuin F (2013) A global wave parameter database for geophysical applications. part 2: Model validation with improved source term parameterization. Ocean Modelling 70:174 - 188, ocean Surface Waves

Rizou D, Flocas HA, Athanasiadis P, Bartzokas A (2015) Relationship between the indian summer monsoon and the large-scale circulation variability over the mediterranean. Atmospheric Research 152:159 - 169, atmospheric Processes in the Mediterranean

775 Rocha J, Carvalho-Santos C, Diogo P, Beça P, Keizer JJ, Nunes JP (2020) Impacts of climate change on reservoir water availability, quality and irrigation needs in a water scarce mediterranean region (southern portugal). Science of The Total Environment 736:139477

Sanderson BM, Wehner M, Knutti R (2017) Skill and independence weighting for multi-model assessments. Geoscientific Model Development 10(6):2379 2395 
Solari S, Losada MÁ (2011) Non-stationary wave height climate modeling and simulation. Journal of Geophysical Research: Oceans 116(C9):C09032

Solari S, Van Gelder P (2011) On the use of vector autoregressive (var) and regime switching var models for the simulation of sea and wind state parameters. Marine Technology and Engineering 1:217-230

Solari S, Moñino A, Baquerizo A, Losada MA (2011) Simulation model for harbor verification and management. Coastal Engineering Proceedings 1(32):management.40, DOI 10.9753/icce.v32.management.40, URL https : //journals.tdl.org/icce/index.php/icce/article/view/1294

Stocker T, Qin D, Plattner GK, Alexander L, Allen S, Bindoff N, Bréon FM, Church J, Cubasch U, Emori S, Forster P, Friedlingstein P, Gillett N, Gregory J, Hartmann D, Jansen E, Kirtman B, Knutti R, Krishna Kumar K, Lemke P, Marotzke J, Masson-Delmotte V, Meehl G, Mokhov I, Piao S, Ramaswamy V, Randall D, Rhein M, Rojas M, Sabine C, Shindell D, Talley L, Vaughan D, Xie SP (2013) Technical Summary, Cambridge University Press, Cambridge, United Kingdom and New York, NY, USA, book section TS, p $33-115$

Strandberg G, Bärring L, Hansson U, Jansson C, Jones C, Kjellström E, Kolax M, Kupiainen M, Nikulin G, Samuelsson P, Ullerstig A, Wang S (2014) Cordex scenarios for europe from the rossby centre regional climate model rca4

Tegegne G, Melesse AM, Worqlul AW (2020) Development of multi-model ensemble approach for enhanced assessment of impacts of climate change on climate extremes. Science of The Total Environment 704:135357

Teutschbein C, Seibert J (2012) Bias correction of regional climate model simulations for hydrological climate-change impact studies: Review and evaluation of different methods. Journal of Hydrology 456-457:12 - 29

Tolman HL, The WAVEWATCH III ${ }^{\circledR}$ Development Group (2016) User manual and system documentation of WAVEWATCH III ${ }^{\circledR}$ version 5.16. Tech. Note 329, NOAA/NWS/NCEP/MMAB, 326 pp. + Appendices

Vitousek S, Barnard PL, Fletcher CH, Frazer N, Erikson L, Storlazzi CD (2017) Doubling of coastal flooding frequency within decades due to sealevel rise. Scientific Reports 7(1):1399

Vousdoukas MI, Mentaschi L, Hinkel J, Ward PJ, Mongelli I, Ciscar JC, Feyen L (2020) Economic motivation for raising coastal flood defenses in Europe. Nature Communications 11(1):1-11

Will A, Akhtar N, Brauch J, Breil M, Davin E, Ho-Hagemann HTM, Maisonnave E, Thürkow M, Weiher S (2017) The cosmo-clm 4.8 regional climate model coupled to regional ocean, land surface and global earth system models using oasis3-mct: description and performance. Geoscientific Model Development 10(4):1549-1586 